which is both concise and lucid, and is well illustrated. Then follows a series of chapters dealing with different groups of spinal disease, commencing logically with congenital anomalies.

Also included is a chapter on radiological diagnosis of vertebral lesions, and another which describes the techniques of vertebral biopsy by needle aspiration.

Each chapter maintains a high standard and contains much informative and thought provoking material. The quality of illustrations and X-ray reproduction generally is good, but some of the $\mathrm{X}$-rays lack definition and the detail is too obscure to demonstrate the points referred to in the text. The micro-photographs are very well reproduced. To aid the reader whose appetite has been whetted, each chapter has a short bibliography appended.

Because of the multiple authorship there is considerable variation in the style of writing, and some of the views expressed are personal opinions which may not receive general acceptance. Several of the chapters are absolutely first class, particularly those dealing with vertebral tumours, cervical spondylosis, ankylosing spondylitis, traumatic paraplegia, and osteoporosis.

Tuberculosis of the spine is discussed in five pages, which may be an indication of the relative infrequency of its occurrence these days but may reflect the editors' problem in keeping this book to manageable proportions.

Mechanical disorders of the spine, too, are dealt with rather briefly, and one would have wished for a fuller discussion of this important subject were more space available.

No book on the subject of the spine would be complete without mention of "functional ' backache and Tegner has contributed a short article on this increasing problem. He does not pull his punches and ends on a note of profound pessimism which I fear is well founded.

The editors and individual authors are to be congratulated on producing a most interesting and useful book. It can be read with enjoyment and profit not only by orthopaedic surgeons but can be thoroughly recommended to all who have to deal wilh natients complaining of ' back trouble.'

\section{MODERN TRENDS IN PATHOLOGY}

Edited by D. H. Collins, M.D., F.R.C.P. Pp. 346 , with 134 illustrations. London: Butterworth \& Co. Ltd. I 959 . £3 ros.

The ' modern trends' series of books, published by Butterworths, have established themselves as an invaluable aid to that increasingly difficult task of ' keeping up to date.' In this volume, Professor Collins has interpreted the term 'pathology' in a very wide sense and has in consequence produced an extremely fascinating book. In particular, it is good to see in a book on pathology, a review by Professor Oakley of his work on the localization of antibody production-work which he has carried out over a considerable number of years. Equally valuable are reviews by Professor Payling Wright on his observations on movements of neurotoxinsD and neuroviruses in the nervous system; bye Professor Pulvertaft on his well-known tissueculture work on normal and abnormal tissues $\overrightarrow{\text { is }}$ and by Professor Gough on occupational disease of the lung.

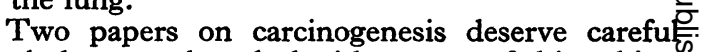
study because they deal with aspects of this subject not normally considered by pathologists in Europe $ฉ$ one by Professor J. N. P. Davies on cancer in Africa, which records some of the fascinatingdifferences between pathological changes seen in Africa as compared with Europe; the second paper -by Professor Steiner-reviews the comples problem of cancer of the liver. Although this review covers a wide field, it is in part comple $\frac{0}{3}$ mentary to Professor Davies' paper for it considers. the reasons for the high incidence of liver cancer in Africans living in Africa or compared with the much lower incidence of those of African descent living in America.

It is an interesting reflection on present-day pathology that in an article, mainly anatomical, on the adrenal cortex Professor Symington has fe은 compelled to include six pages on the chemistry of steroid hormones although it is doubtful if manyक्p his readers will gain much from this introductiog They will, however, learn much from the descrip tions of the anatomical changes in the gland ing different diseases.

Among other subjects covered, there are teresting chapters on 5-hydroxytryptamine, whā body irradiation and the acute inflammator reaction.

In all this book contains ${ }_{5} 5$ chapters all of which maintain a high standard. They provide a valuable survey of the immense strides made during the lasf few years in the study of body tissues. The editor is to be congratulated. The book is well produced and well illustrated.

\section{CARDIOVASCULAR SOUND IN HEALTF AND DISEASE}

By. Victor A. McKusick, M.D. Pp. xii +570 with 494 illustrations: London: BaillièreO Tindall \& Cox, Ltd. 1958. $£ 6$.

Dr. McKusick dedicates his monograph on cardiovascular sound to the memory of Willians Harvey and the Father of modern physiology. would have been pleased with it. $\mathrm{He}$ was weli aware of the "pulse that can be heard within the chest.' Indeed his reference to heart sounds is 0 according to Dr. McKusick the earliest and clearest which survives-no mean compliment in $\sigma_{6}$ text which lists 1607 references. Everything of interest to the physician relating to cardiovascular sound is herein compiled in an orderly and masterlyo fashion. The historical survey, delightfully bal -- 
anced and illustrated shows the author to be a scholar, and the section on auscultation in heart disease, the crucial part of the monograph, is wellinformed and well-documented. And how reassuring it is to find a contemporary American author whose interest and vision extends beyond the limits of the United States !

The illustrations are mainly 'spectral phonocardiograms' (or ' sound spectrograms'), known in this country only through the writing of the author and a few others. The principle is best understood by considering the heart sounds, in electrical form, being passed through a large number of electrical filters each of which is tuned to a different and specific frequency. The output of each filter activates a tiny bulb. The play of the bank of lights on a moving film inscribes the spectral phonocardiogram. The vertical scale represents frequency, and the density of the recording indicates the intensity of the noise. The author claims a number of advantages for this technique. Theoretically irrefutable, these merits stand or fall depending on the technical perfection of the record. The murmurs of pure severe aortic or pulmonary stenosis or mitral incompetence produce beautiful pictures by this method, as they do by the conventional oscillographic technique. A poor record merely presents an auscultatory problem to the eye instead of the ear and nothing is gained. The spectral phonocardiogram seems to be the weakest when precise timing of events is crucial because the standard reference tracing, the electrocardiogram, is almost invariably blurred. This may be due to a technical defect in one of the several stages of the technique. If it can be remedied and the detail of the sound recording improved, spectral phonocardiography may well fulfil the author's prediction of becoming the method of choice in this field.

\section{OBSTETRICS}

By Sir Eardley Holland. Pp. xiv + 1228, illustrated. London: William Heinemann, Medical Books Ltd. 1959. $147 \mathrm{~s}$.

This book, like its companion work on gynaecology, is designed for postgraduates, be they those working for higher degrees or those carrying out postgraduate practice of obstetrics either in hospital or in general practice. It is, however, not a complete guide to practical obstetrics in the way that books reserved for operative obstetrics are. It is a work, that in $4 \mathrm{I}$ chapters, authoritatively and thoroughly deals with the theory, as well as the practice, of every part of obstetrics from the physiology of conception through the care of the pregnant woman, the management of her labour and puerperium, to a discussion of the kindred subjects of obstetrics and psychology, and obstetrics and the law.

If the chapter on Caesarean Section is singled out because of the occasional beauty of its English, the fluency of its style, the fullness of its information; and the fairness of its comparison of statistics from different sources, it is not because it is necessarily the best chapter in the book. It comes, from the Liverpool school and, for this edition has. been written by Mr. C. J. K. Hamilton, who revised the late Charles Macintosh Marshall's chapter.

I particularly liked, too, the original approach of Mr. Ian Jackson to Maternal Injuries and Dystocia due to deformities of the foetus.

Each chapter is written by a man who has made that particular part his special interest.

The illustrations are superb, the references at the end of each chapter are extensive and by and large, most of the writing is easy to read. Where there are something like 35 authors contributing to a book, obviously there is some unevenness in the style of writing throughout the book, but the editing of Sir Eardley Holland has been skilful enough to smooth out most of this unevenness and to avoid, as far as I can see, any useless repetition.

This textbook, together with the one on gynaecology, would probably today represent the sum total of the reading necessary by the candidate for the M.R.C.O.G. examination. In fact, I should say that if he had read both these books completely from cover to cover, he would not need to turn to any other book, except possibly for revision to a more basic and smaller textbook. Once more, William Heinemann Ltd. are to be congratulated on the excellence of their production, which is a credit to British publishing.

\section{BIGGER'S HANDBOOK OF BACTERIOLOGY}

By F. S. Stewart, M.D.(Dublin), F.R.C.P.I. 7 th edition. Pp. $x+6 r$, illustrated. London: Baillière, Tindall \& Cox. 1959. 37s. 6d.

Professor Stewart has succeeded in giving us one of the best textbooks for medical students that has been published since the war. Earlier editions of Bigger's book were first class, but it has not been possible to use it recently, as so many fundamental changes have taken place in microbiology in the last ro years.

In rewriting, the old scaffolding may have been used, but so much of the material is fresh that it is virtually a new book with the outlook and personality of its present author impressed on it. It is clearly the work of an experienced teacher and every page is furrowed with the efforts to decide what can be best left out. I was particularly impressed by his courage in excluding the formulae of media and - similar minutae. At the same time he indicates the important ingredients in a medium and gives detailed instruction for its use in diagnosis.

Another outstanding virtue is that new discoveries and observations have been neatly fitted into the text as brief references, even though in some cases the papers from which they were taken can only have been heard at scientific meetings at 